\title{
Student self-assessment after Essential Surgical Skills training for final-year medical students at Gulu University, northern Uganda
}

\author{
Tom R. Okello ${ }^{1,2}$, Patrick Mugabi², Ghee Hwang ${ }^{3}$, Michelle Sutter ${ }^{3}$, Ronald Lett ${ }^{3}$ \\ 1. Gulu University School of Medicine, Gulu, Uganda \\ 2. Department of Surgery, St. Mary's Hospital Lacor, Gulu, Uganda \\ 3. International Surgery Committee, Canadian Association of General Surgeons, Ottawa, Ontario, Canada
}

Correspondence: DrTom R. Okello (okellotomrich@yahoo.co.uk)

(C) 2018 T.R. Okello et al. This open access article is licensed under a (reative Commons Attribution 4.0 International License (http://creativecommons.org/licenses/by/4.0/), which permits unrestricted use, distribution, and reproduction in any medium, provided you give appropriate credit to the original author(s) and the source, provide link to the Creative Commons license, and indicate if changes were made.

\begin{abstract}
Background

Medical practice depends on a set of essential clinical and surgical skills, yet inadequate attention is given to training these skills in medical school. This study aimed to evaluate the effect of Essential Surgical Skills ${ }^{\oplus}$ (ESS) training on self-report comfort levels in performing surgical skills among final-year medical students at Gulu University in Gulu, Uganda.

\section{Methods}

This study analysed 5 years' worth of pre- and post-course ESS self-evaluation questionnaires completed by final-year medical students attending Gulu University between 2013 and 2017. Pre- and post-course results were compared using Student's t-test. ESS elements covered over the 5-day course were: surgery fundamentals; respiratory and anaesthesia skills; and skills related to gastrointestinal, obstetric, and orthopaedic surgery.
\end{abstract}

\section{Results}

There was a significant improvement in the students' level of comfort related to all ESS components when pre- and post-course questionnaire responses were compared $(P<0.001)$

\section{Conclusions}

Medical schools should emphasize training of essential clinical and surgical skills because these give medical students the confidence and proficiency needed in clinical practice.

Keywords: surgical skills, education, training, medical school, Uganda, Somalia

\section{Introduction}

Practical clinical and surgical skills are given minimal emphasis in the curriculums of many medical schools, yet medical and surgical practice critically depend on these very skills. A study in the USA found that the majority of medical schools $(n=60 ; 78 \%)$ teach no clinical skills, other than an introduction to phlebotomy. ${ }^{1}$ After experimenting with short simulator-based training, students in the UK, Germany, and Greece immediately advocated that essential surgical skills training be included in their undergraduate curriculums. ${ }^{2}$ In another study, $90 \%$ of students who took surgical skills training were pleased with the knowledge and skills gained and recommended that skills training become compulsory in all medical schools. ${ }^{3}$ Medical students need skills training, and it is important for universities to redirect efforts and resources to skills training. To address identified gaps in surgical skills training for medical students, the Canadian Network for International Surgery (CNIS) oversees and sponsors Essential Surgical Skills ${ }^{\bullet}$ (ESS) teaching in Ethiopia, Mali, Rwanda, Tanzania, and Uganda. ${ }^{4}$

At the Gulu University School of Medicine, clinical and surgical skills training has been offered to final year medical students for the last 10 years; however, the effectiveness of this training - in terms of students' skill acquisition and confidence-has never been formally evaluated. 
This study aimed to examine whether the ESS training provided Gulu University medical students with the confidence to perform important surgical procedures.

\section{Methods}

Final-year medical students at Gulu University (including students enrolled with Somali International University but undergoing their final year of training at Gulu) were offered 5 days of structured essential surgical skills training in the Faculty of Medicine between 2013 and 2017. Specialists in obstetrics, orthopaedics, general surgery, and anaesthesia conducted the training using a standardized structured course manual, along with models and manikins, biological materials, medical supplies, and sundries. Where specialists were lacking, senior and principal clinical officers conducted the training. Each student was exposed to at least one the skill training station per day.

The surgical skills consisted of:

1. Fundamental skills, which included proper scrubbing, gowning, gloving, and draping; surgical knots; laceration repair on animal legs and heads; and venous cutdown on a built model.

2. Anaesthesia and respiratory skills, which included the performance of endotracheal intubation and cardiopulmonary resuscitation (CPR) on manikins, insertion of chest tubes using goat's chest wall, and use of ketamine anaesthesia.

3. Gastrointestinal and abdominal surgery skills, which involved laparotomy on a built model, colostomy, bowel anastomosis using cow intestines, and nasogastric tube insertion using a manikin.

4. Obstetrical training included normal delivery, breech delivery, vacuum delivery, caesarean section, and shoulder dystocia using manikins, vacuum extractors, and obstetric forceps.

5. Urological skills training included the performance of urethral catheterization on a pelvic bladder model, use of filiform and followers for dilatation of urethral strictures, and suprapubic cystostomy (SPC) on models.

6. Orthopaedic skills training included limb $\mathrm{x}$-ray reading, plaster of Paris (POP) application, and skin and skeletal traction application, using fellow students as subjects.

Before the training, the students were given a self-administered pre-course test, which used a Likert scale to appraise the learners' competencies and performance status related to the above skills. After the 5 days of hands-on training, the students completed a similar questionnaire. Pre- and postcourse test results were analysed using SPSS version 15 (SPSS Inc., Chicago, IL, USA). Student's t-test was used to analyse the difference between the pre- and post-training competencies and performance status; $P$ values of 0.05 and below were considered statistically significant.
Table 1. Student demographic characteristics

\begin{tabular}{r|c|c}
\hline \multicolumn{1}{c|}{ Category } & $\mathbf{n}$ & \% \\
\hline \hline Age (years) & & \\
$20-25$ & 83 & 63 \\
$26-31$ & 42 & 32 \\
$32-37$ & 5 & 4 \\
$38-43$ & 1 & 1 \\
\hline Sex $\quad$ Male & 102 & 78 \\
Female & 29 & 22 \\
\hline Nationality & & \\
Ugandan & 106 & 81 \\
Somalian & 25 & 19 \\
\hline Total & 131 & \\
\hline
\end{tabular}

\section{Results}

The analysis includes data for 131 students who underwent ESS training at Gulu University between 2013 and 2017, and the key findings are summarized in Table 1 and Table 2.

Student age ranged from 22 to 41 years (mean $=25.5$ years; standard deviation $[\mathrm{SD}]=2.85$ years). The majority of students $(63 \%)$ were in the 20 - to 25 -year age group; $32 \%$ were between 26 and 31 years of age, $4 \%$ were between 32 and 37 years old, and 1\% were between 38 and 43 years of age. Most participants (78\%) were male. During the study period, the final-year medical student cohort at Gulu University included students from Somali International University; this study included 106 (81\%) Ugandan students from Gulu University, with the remainder $(\mathrm{n}=25 ; 19 \%)$ being Somali students from Somali International University.

Table 2 presents the students' pre- and post-training self-reported comfort levels related to the skills covered in the ESS course. Before undergoing ESS training, nearly half of the students $(n=60 ; 46 \%)$ were unaware of, or unable to, perform the fundamental skills of scrubbing, gowning, gloving, laceration repair, cutdown, knot tying, and elliptical excision of skin lesions; 37 students $(28 \%)$ reported that they were "uncomfortable" and 30 (23\%) reported that they were "comfortable" with these procedures. However, after the training, 100 students $(76 \%)$ reported that they were "very comfortable" performing these skills and 30 (23\%) were comfortable; 1 student reported a lack of awareness or ability related to these procedures $(P<0.001)$ after the ESS training. Similar trends were observed in the all of the other ESS components.

In the respiratory and anaesthesia skills module, 27 (21\%) and 66 (50\%) students were, respectively, "very uncomfortable" and "comfortable" with their performance of $\mathrm{CPR}$, adult endotracheal intubation, chest tube insertion, and ketamine administration for anaesthesia. However, after the training, $79(60 \%)$ and $49(37 \%)$, respectively, reported 
Table 2. Pre-and post-course student self-assessment responses

\begin{tabular}{|c|c|c|c|c|c|c|}
\hline \multirow{2}{*}{ Assessment category } & \multicolumn{5}{|c|}{ Self-assessment response $\mathrm{n}(\%)$} & \multirow{2}{*}{$P$ value } \\
\hline & Very uncomfortable & Uncomfortable & Don't know & Comfortable & Very comfortable & \\
\hline $\begin{array}{l}\text { Pre-course fundamental skills and } \\
\text { performance: scrubbing, gowning, gloving, } \\
\text { laceration repair, cutdown }\end{array}$ & $4(3)$ & $37(28)$ & $60(46)$ & $30(23)$ & 0 & \multirow{2}{*}{$<0.001$} \\
\hline $\begin{array}{l}\text { Post-course fundamental skills and } \\
\text { performance: scrubbing, gowning, gloving, } \\
\text { laceration repair, cutdown }\end{array}$ & 0 & 0 & $1(1)$ & $30(23)$ & $100(76)$ & \\
\hline $\begin{array}{l}\text { Pre-course respiratory and anaesthesia } \\
\text { skills and performance: CPR, endotracheal } \\
\text { intubation, chest tube, ketamine anaesthesia }\end{array}$ & $27(21)$ & $66(50)$ & $27(21)$ & $11(8)$ & 0 & \multirow{2}{*}{$<0.001$} \\
\hline $\begin{array}{l}\text { Post-course respiratory and anaesthesia } \\
\text { skills and performance: CPR, endotracheal } \\
\text { intubation, chest tube, ketamine anaesthesia }\end{array}$ & 0 & $1(1)$ & $2(2)$ & $49(37)$ & $79(60)$ & \\
\hline $\begin{array}{l}\text { Pre-course abdominal surgery skills } \\
\text { and performance: laparotomy, bowel } \\
\text { anastomosis, nasogastric tube insertion }\end{array}$ & $8(6)$ & $61(47)$ & $53(40)$ & $9(7)$ & 0 & \multirow{2}{*}{$<0.001$} \\
\hline $\begin{array}{l}\text { Post-course abdominal surgery skills } \\
\text { and performance: laparotomy, bowel } \\
\text { anastomosis, nasogastric tube insertion }\end{array}$ & 0 & 0 & $6(5)$ & $60(46)$ & $65(50)$ & \\
\hline $\begin{array}{l}\text { Pre-course obstetric delivery skills and } \\
\text { performance: normal, vaccum, breech, } \\
\text { shoulder dystocia }\end{array}$ & $3(2)$ & $47(36)$ & $58(44)$ & $20(15)$ & $3(2)$ & \multirow{2}{*}{$<0.001$} \\
\hline $\begin{array}{l}\text { Post-course obstetric delivery skills and } \\
\text { performance: normal, vaccum, breech, } \\
\text { shoulder }\end{array}$ & 0 & 0 & $4(3)$ & $52(40)$ & $75(57)$ & \\
\hline $\begin{array}{l}\text { Pre-course urology skills and performance: } \\
\text { catheterization, dilatation of stricture, } \\
\text { suprapubic cystotomy }\end{array}$ & $5(4)$ & $61(47)$ & $53(40)$ & $12(9)$ & 0 & \multirow{2}{*}{$<0.001$} \\
\hline $\begin{array}{l}\text { Post-course urology skills and performance: } \\
\text { catheterization, Stricture, dilatation, } \\
\text { suprapubic cystotomy }\end{array}$ & 0 & 0 & $3(2)$ & $36(27)$ & $92(70)$ & \\
\hline $\begin{array}{l}\text { Pre-course orthopaedic skills and } \\
\text { performance: reading limb x-ray, plaster of } \\
\text { Paris application, and skeletal traction }\end{array}$ & $4(3)$ & $39(30)$ & $59(45)$ & $27(21)$ & $2(2)$ & \multirow{2}{*}{$<0.001$} \\
\hline $\begin{array}{l}\text { Post-course orthopaedic skills and } \\
\text { performance: reading limb } x \text {-ray, plaster of } \\
\text { Paris application, and skeletal traction }\end{array}$ & 0 & 0 & $2(2)$ & $50(38)$ & $79(60)$ & \\
\hline
\end{tabular}

being "very comfortable" and "comfortable" in performing these skills $(P<0.001)$.

Regarding abdominal surgery skills, the pre-course questionnaire analysis revealed that 61 students (47\%) were "uncomfortable" with their ability to perform laparotomies, bowel anastomoses, colostomies, and nasogastric tube insertions; 53 students (40\%) were unaware of, or unable to, perform these procedures. However, after the course, $60 \mathrm{stu}-$ dents (46\%) reported being "comfortable" with these skills, and $65(50 \%)$ were "very comfortable" $(P<0.001)$.

Whereas 47 (36\%) and 58 (44\%) students, respectively, were "uncomfortable" with or did not know any obstetric skills related to normal delivery, vacuum delivery, breech delivery, and shoulder dystocia before the ESS training; 53 (40\%) were "comfortable" and 75 (57\%) were "very comfortable" with their performance of these skills after the training $(P<0.001)$.

Regarding the orthopaedic skills of reading limb x-rays, POP application, and skeletal and skin traction, before the ESS course, 39 students (30\%) were "uncomfortable", and 59 (45\%) lacked the requisite knowledge or ability to perform these skills. However, after the training, 79 (60\%) were "very comfortable", and 50 (38\%) were "comfortable" with carrying out these procedures $(P<0.001)$.

Post-course self-appraisal of urologic skill performance (including urethral catheterization, stricture dilatation, and SPC insertion) was also significantly better than the precourse self-appraisal $(P<0.001$; Table 2$)$.
In terms of self-evaluation regarding any of the ESS components, there was no significant difference between males and females nor among the different age groups or nationalities included in the analysis.

\section{Discussion}

The increasing complexity of surgical diseases and the need to limit medical and surgical errors on patients during internship and beyond, necessitate that basic surgical skills are learned and practised on models and simulators in medical school. ${ }^{5}$ Practical training better equips medical students with much-needed clinical and surgical skills. In some centres, computerized simulator surgical skills training has replaced hands-on bench models; notably, a study found that errors were 6 times less likely to occur in students trained with computer-generated skills ( 1.19 vs 7.38 errors per case; $P=0.008)$ compared to those who only had hands-on training. ${ }^{6}$ In many university medical schools, there is a growing demand for essential surgical skills training before students graduate. ${ }^{2,3}$ At Gulu University, essential surgical skills training is part of the curriculum and is offered to all final year medical students.

The mean age of 25.5 years ( $\mathrm{SD}=2.85$ years) and the male student predominance among final year medical students at Gulu university is similar to that of their counterparts in Nigeria. ${ }^{7}$ A separate study in South Africa also found final year medical students' mean age to be $24.7 \pm 3.3$ years. ${ }^{8}$ In the present study, in terms of self-reported confidence regard- 
ing surgical skills before and after the training, there was no significant difference among the age groups, sexes, and nationalities.

This study has demonstrated that confidence related to essential surgical and clinical skill competencies can be imparted through a dedicated structured training programme, parallel to the usual curricular lectures, tutorials, bedside, and practical sessions. However, drawbacks might include the difficulty involved in merging such programmes into a university's existing assessment and grading scheme.

Most students included in this study were either uncomfortable with or did not know about the ESS components before the course. However, the students' level of comfort with all skills improved significantly after taking part in the course. A study by Denadai, Oshiiwa and Saad-Hossne $e^{9}$ also found that the analysis of pre- and post-course output of students trained in elliptical lesion excision showed a significant improvement in the students' confidence and performance global rating. Another study that compared preand post-training suturing skills among 36 medical students demonstrated a statistically significant improvement in skill performance after hands-on training. ${ }^{10}$ Undergoing practical skills training during medical schools helps students discover their career potential early and may prevent errors, malpractice, and criticism that could lead to undesirable outcomes for patients, litigation, and impeded career progress for students and junior doctors. ${ }^{11,12}$

\section{Competing interests}

All authors declare that they have no competing interests related to this work.

\section{References}

1. Nelson MS, Traub S. Clinical skills training of U.S. medical students. Acad Med. 1993 Dec;68(12):926-8.

2. Sideris $M$, Papalois $A$, Theodoraki K, Dimitropoulos I, Johnson EO, Georgopoulou EM, et al. Promoting undergraduate surgical education: current evidence and students' views on ESMSC International Wet Lab Course. J Invest Surg. 2017 Apr;30(2):71-77. doi: 10.1080/08941939.2016.1220652. Epub 2016 Sep 9.

3. Breitmeier $D$, Schulz $Y$, Wilke $N$, Albrecht K, Haeseler G, Panning B, et al. [Cricothyroidotomy training on cadavers - experiences in the education of medical students, anaesthetists, and emergency physicians]. [Article in German] Anasthesiol Intensivmed Notfallmed Schmerzther. 2004 Feb;39(2):94-100. doi: 10.1055/s-2004-817678.

4. ESSENTIAL SURGICAL SKILLS ${ }^{\circledast}$ (ESS) [Internet]. Vancouver (Canada): Canadian Network for International Surgery; c2009-2016. Available from: http://www. cnis.ca/what-we-do/safer-surgical-andobstetrics-program/ess/.
5. Reznick RK, MacRae H. Teaching surgical skills--changes in the wind. N Engl J Med. 2006 Dec 21;355(25):2664-9. doi: 10.1056/ NEJMra054785.

6. Seymour NE, Gallagher AG, Roman SA, O'Brien MK, Bansal VK, Andersen DK, et al. Virtual reality training improves operating room performance: results of a randomized, double-blinded study. Ann Surg. 2002 Oct;236(4):45863; discussion 463-4. doi: 10.1097/01. SLA.0000028969.51489.B4.

7. Ossai EN, Uwakwe KA, Anyanwagu UC, Ibiok NC, Azuogu BN, Ekeke N. Specialty preferences among final year medical students in medical schools of southeast Nigeria: need for career guidance. BMC Med Educ. 2016 Oct 4;16(1):259. doi: 10.1186/s12909-016-0781-3.

8. de Vries E, Irlam J, Couper I, Kornik S Health Equity through Education and Research (CHEER). Career plans of finalyear medical students in South Africa. S Afr Med J. 2010 Mar 30;100(4):227-8.
9. Denadai R, Oshiiwa M, Saad-Hossne R. Teaching elliptical excision skills to novice medical students: a randomized controlled study comparing low- and high-fidelity bench models. Indian J Dermatol. 2014 Mar;59(2):169-75. doi: 10.4103/0019-5154.127679.

10. Denadai R, Oshiiwa M, Saad-Hossne R. Does bench model fidelity interfere in the acquisition of suture skills by novice medical students? Rev Assoc Med Bras (1992). 2012 Sep-Oct;58(5):600-6. doi; 10.1590/S0104-42302012000500019.

11. Lee JY, Kerbl DC, McDougall EM, Mucksavage P. Medical students pursuing surgical fields have no greater innate motor dexterity than those pursuing nonsurgical fields. J Surg Educ. 2012 May-Jun;69(3):360-3. doi: 10.1016/j. jsurg.2011.11.005.

12. Flinn JT, Miller A, Pyatka N, Brewer J, Schneider T, Cao CG. The effect of stress on learning in surgical skill acquisition. Med Teach. 2016 Sep;38(9):897-903. doi: 10.3109/0142159X.2015.1114597. Epub 2015 Dec 8. 